Research Article

\title{
Day-Ahead Scheduling for Renewable Energy Generation Systems considering Concentrating Solar Power Plants
}

\author{
Xiaojuan Lu $(\mathbb{D})$ and Leilei Cheng \\ School of Automation and Electric Engineering, Lanzhou Jiaotong University, Lanzhou 730070, China \\ Correspondence should be addressed to Leilei Cheng; 0619371@stu.lzjtu.edu.cn
}

Received 19 May 2021; Accepted 13 August 2021; Published 24 August 2021

Academic Editor: Raffaele Carli

Copyright (C) 2021 Xiaojuan Lu and Leilei Cheng. This is an open access article distributed under the Creative Commons Attribution License, which permits unrestricted use, distribution, and reproduction in any medium, provided the original work is properly cited.

\begin{abstract}
With the advent of the new types of electrical systems that attach more importance to the renewability of the energy resource, issues arising out of the randomness and volatility of the renewable energy resource, such as the safety, reliability, and economic operation of the underlying power generation system, are expected to be challenging. Generally speaking, the power generation company can do a reasonable dispatch of each unit according to weather forecast and load demand information. Focusing on concentrating solar power (CSP) plants (wind power, photovoltaic, battery energy storage, and thermal power plants), this paper proposes a day-ahead scheduling model for renewable energy generation systems. The model also considers demand response and related generator set constraints. The problem is described as a mixed-integer nonlinear programming (MINLP) problem, which can be solved by the CPLEX solver to obtain an optimal solution. At the same time, the paper compares and analyzes the impact of concentrating solar power plants on other renewable energy generation and thermal power operation systems. The results show that the renewable energy generation system can lower power generation costs, reduce load fluctuation, and enhance the energy storage rate.
\end{abstract}

\section{Introduction}

As the world's largest energy producer and consumer, China has made it clear that it will strive to reach carbon emissions peaks by 2030 and then suppress carbon emissions until complete neutrality is achieved by 2060 . With regard to realizing these two "dual-carbon" goals, promoting the construction of high-proportion renewable energy systems is expected to become a trend. New clean energy technologies must replace traditional thermal power systems to undertake peak shaving as well as heat supply tasks. CSP technology is a type of renewable energy generation that uses thermoelectric conversion to generate electricity from solar thermal resources. This technology, which is undoubtedly an ideal clean energy technology choice, has been demonstrated in China and achieved certain results.

The existence of uncertainty is one of the main challenges in the energy scheduling problem of integrating renewable energy. In order to deal with this problem, [1] describes the uncertainty problem as a multiobjective optimization problem and proposes an optimal day-ahead scheduling method for renewable energy based on the NSGA-II algorithm. However, the effect of energy storage systems has not been considered in renewable energy power generation. Reference [2] uses the dispatchability of CSP plants to integrate CSP plants with wind farms, which reduces output uncertainty, improves overall regulation efficiency, and proves that the addition of CSP plants can increase the reliability of renewable energy power generation systems. Therefore, it is of great significance to analyze the scheduling problems of renewable energy power generation systems including CSP plants and energy storage systems. In addition, the impact of CSP plants on the cost of other renewable energy generation and thermal power generation systems is also worth discussing. From the system structure perspective, [3] proposes a novel robust framework using for day-ahead energy dispatch of residential microgrids, which solved the double uncertainty caused by renewable energy 
and user behavior. Therefore, the relationship between power generation and load demands needs to be effectively balanced by grid operators [4,5]. Solving the reliability problem of the renewable energy generation systems through microgrid technology is an essential means [6]. The types of distributed power generation, generally contained in the power generation side of the microgrid, are wind power, photovoltaics, small gas turbine systems, and battery energy storage systems, as well as other dispatchable resources. The energy management system (EMS) considers system constraints and demand response to perform reasonable dispatch operations on the power generation side, which can effectively increase the profitability of the power generation and the penetration rate of the renewable energy system [7-11]. However, one limitation of microgrid is that it only provides a solution for small distributed power generation systems [12]. Therefore, related studies have proposed using load-side changes to adjust to the uncertainties of renewable energy resources while generating electricity. Reference [13] established a nonlinear model of the demand response programs (DRPs) based on incentives and examined the influence of derivative models on elastic changes, incentives, penalties, and implementation potential and then determined the degree of dependent models. Reference [14] proposed a dispatching optimization model of wind power based on the robust stochastic optimization theory, which considers different demand responses. The simulation results show that the robust stochastic optimization theory can overcome wind power uncertainties and that the two demand response methods have the most substantial effect on wind power absorption. Song et al. [15] showed that, in response to wind power consumption, the demand response and energy storage technology are added to the power generation dispatches. A large-scale wind power dispatch model is constructed with optimization goals such as economic maximization. The simulation results show that the combined effect of the demand response and the energy storage technology has helped improve the system's wind power consumption capacity. The system's coal consumption level of power generation has decreased. Astriani et al.[16] addressed the problem of demand response, with respect to reducing customer comfort, and proposed an incentive scheme feasible for demand-side participants as well as for grid operators. The results show that distributing part of the profits to consumers as an incentive to participate in the program can increase the profits of the grid company. References [17-19] proposed using electric vehicles and battery energy storage to participate in response dispatches; the charging prices for electric cars were optimized; thus, the loads are adjusted, cooperation with the energy storage battery was utilized, and finally, the goal of maximizing profits was achieved. References [20,21] studied the ability of temperature-controlled loads to adjust the loads. The simulation results show that temperature-controlled load adjustment can reduce system cost and increase system reliability. In addition to general commercial and residential loads participating in the response, [22] suggested that demand-responsive industrial loads with high thermal inertia can participate in the power market frequency regulation. The simulation results show that an industrial park with a capacity of $500 \mathrm{MW}$ can provide ancillary services with a capacity of up to $40 \mathrm{MW}$ to participate in secondary frequency modulation. Liao et al. [23] proposed using the direct control scheme of the high energy-consuming loads to smooth wind power fluctuations. The above demand response model covers residential electricity, commercial electricity, industrial electricity, and flexible load regulation, which can effectively improve renewable energy generation consumption and grid security. However, the adjustable load-side response capacity is limited and its response is a passive response. Therefore, combining the demand-side response and the renewable energy generationside dispatch is particularly critical.

Zhao et al.[24] considered the uncertainties of wind power and the limitations of the power grid and used the probability method to solve the wind power capacity limit. Reference [25] proposed integrating wind power and energy storage into the power system. The research results show that energy storage devices can reduce the operational risk to an acceptable level. The focus of [26] was on the congestion problem of renewable energy generation channels; utilization of energy storage units was proposed to solve the uncertainties of both wind and solar resources. Using Gaussian probability distribution function modeling and the Monte Carlo simulation, this method effectively alleviates the congestion problem of renewable energy generation lines. Reference [27] proposed solving the PV power prediction error caused by the forecast error; the energy storage system was used to compensate for the uncertain power of the photovoltaic power station and to realize the excellent playability of the photovoltaic resources. However, the battery energy storage currently suffers from such issues as high costs, service life, and safety. The technology of concentrating solar power in accordance with a heat storage system can play an important role in renewable energy generation systems [28].

Unlike other renewable energy generation systems, CSP plants with heat storage systems can make energy use rational. Furthermore, the CSP power generation system is similar to the thermal power unit; therefore, it has more flexible adjustment capabilities [29]. Reference [30] compared the power generation costs of CSP plants and gas turbines. The results show that hybrid solar power plants have proved to be more cost-effective under certain conditions while maintaining significant scheduling and flexibility capabilities. Compared to wind and photovoltaic power generation systems, CSP generation systems also claim higher competitiveness [31]. Reference [32] established a general model framework for an optimal CSP plants supply strategy, under the combined conditions of the energy market, reserve, and supervision. The results show that the provision of ancillary services significantly increases the profits of CSP plants. Reference [33] took wind power plants in the Iberian Peninsula and CSP plants as examples; the short-term coordination of wind farms and CSP plants was studied. The results show that the combined power generation system can increase the profit of power generation enterprises, in addition to increasing the transmission 
capacity coefficient. The focus of [34] was on the problem of wind power consumption; a dispatch model based on CSP and price-based demand response participation in the consumption of wind power was proposed. The results show that the application of the price-based demand response and the involvement of the CSP plant in formulating an optimal dispatch can make up for the insufficiency of the wind power antipeak-shaving characteristics, improve wind power consumption, and reduce the overall system costs. Reference [35] proposed a model that considers CSP plants and compressed air energy storage to address the traditional unit combination problem. The simulation results show that adding CSP plants and compressed air energy storage systems can effectively increase the profits of the power generation companies. Based on the above researches and the actual energy situation in Northwest China, this paper proposes a renewable energy generation system dispatch model that considers CSP plants. By comparing four different cases, the paper analyzes the impact the access of the CSP plant has on thermal power, wind power, and battery energy storage, as well as other systems.

The rest of the paper is organized as follows. Section 2 focuses on the system models, including the CSP model, the wind power model, the photovoltaic model, the battery energy storage model, and the demand-side response model. In Section 3, four different cases are given along with their simulation analyzes. Finally, the conclusion of the paper is given in Section 4.

\section{System Models}

This section alludes to the system mathematical models, which include the CSP plant model, the wind power model, the photovoltaic model, the battery energy storage model, the demand response model, the thermal unit model, and the system's constraints. The objective function of the system is expressed as follows:

$$
\min \operatorname{cost}=\sum_{t=1}^{T}\left(\operatorname{cost}_{t}^{\mathrm{CSP}}+\operatorname{cost}_{t}^{\mathrm{WD}}+\operatorname{cost}_{t}^{\mathrm{PV}}+\operatorname{cost}_{t}^{G}\right) .
$$

This paper takes the minimum total power generation cost of the system as the objective function. Thus, the total cost is the sum of the cost concentrating solar power generation, wind power cost, and photovoltaic and thermal power.

2.1. Concentrating Solar Power Plant Model. The cost function of the CSP plant can be described as a linear function of the generation power. The objective function is expressed as follows:

$$
\operatorname{cost}_{t}^{\mathrm{CSP}}=k^{\mathrm{CSP}} P_{t}^{\mathrm{CSP}} \text {. }
$$

According to the heat storage characteristics, the CSP plant can be divided into two types: without thermal energy storage (TES) and with TES. The CSP plant without TES has a small area, low initial investment cost, poor dispatch ability, and long gas turbines equipment times. The CSP plant with TES is generally large-scale. The power generation system can be dispatched reasonably through TES to maximize the use of solar energy and reduce the impact of renewable energy on the power grid. A simplified structure diagram of the CSP plant with a TES is shown in Figure 1.

The CSP plant comprises three systems: the solar field (SF), TES, and the power block (PB). The three systems transfer heat through the heat transfer fluid (HTF). The SF transfers heat to HTF by absorbing the solar heat. HTF transfers heat to the $\mathrm{PB}$ through flows to generate a hightemperature and high-pressure steam to drive steam turbines and generate electricity or flow into the thermal energy storage (TES) to the heat directly. The TES can also transfer stored heat to the PB through HTF for power generation. The energy conversion relationship of the CSP plant is shown in Figure 2 [33].

When considering the CSP plant model, most of the losses, incurred during the energy conversion process, happen during the light-to-heat and thermoelectric conversion processes. In contrast, the HTF and TES heat losses are relatively small. Therefore, we simplified the heat loss model.

The CSP plant mathematical model can be described as formulas (3)-(16) [31]. Equations (3)-(5) represent the output power balance of the CSP plant. Equation (6) represents the lowest and highest acceptable heat of the generator. Equation (7) expresses the constraint of the SF heat output to the generator. Equation (8) represents the SF input and output constraints. Equation (9) represents the TES balance constraint. Equation (10) represents the TES capacity constraint. Equation (11) expresses the generator output capacity constraint. Equations (12) and (13) represent the charging and discharging climbing power constraints of the TES. Equations (14) and (15) represent the upper and lower limits of the charge and discharge of the TES; the TES cannot be charged and discharged at the same time.

$$
\begin{gathered}
P_{t}^{\mathrm{CSP}}=P_{t}^{\mathrm{SP}}+P_{t}^{\mathrm{TP}}, \\
P_{t}^{\mathrm{SP}}=\eta_{1} q_{t}^{\mathrm{SP}}, \\
P_{t}^{\mathrm{TP}}=\eta_{2} q_{t}^{\mathrm{TP}}, \\
q^{\mathrm{PB} \min } \leq q_{t}^{\mathrm{SP}}+q_{t}^{\mathrm{TP}} \leq q^{\mathrm{PB} \max }, \\
q^{\mathrm{SP} \min } \leq q_{t}^{\mathrm{SP}} \leq q^{\mathrm{SP} \max }, \\
q_{t}^{\mathrm{SP}}+q_{t}^{\mathrm{SE}} \leq q_{t}^{\mathrm{SP}}, \\
q_{t}^{\mathrm{TES}}=q_{t-1}^{\mathrm{TES}}+q_{t}^{\mathrm{ST}}-q^{\mathrm{TP}}, \\
q^{\mathrm{TES} \min } \leq q_{t}^{\mathrm{TES}} \leq q^{\mathrm{TES} \max }, \\
P^{\mathrm{CSP} \min } \leq P_{t}^{\mathrm{CSP}} \leq P^{\mathrm{CSP} \max }, \\
\mathrm{RD}^{\mathrm{TP}} \leq q_{t}^{\mathrm{TP}}-q_{t-1}^{\mathrm{TP}} \leq \mathrm{RU} \mathrm{TP}^{\mathrm{TP}},
\end{gathered}
$$




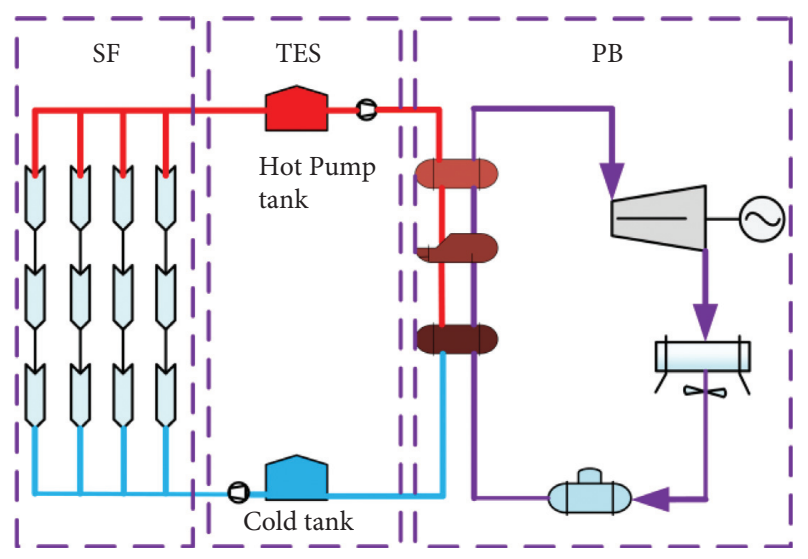

FIGURE 1: Simplified structure diagram of a CSP plant with TES.

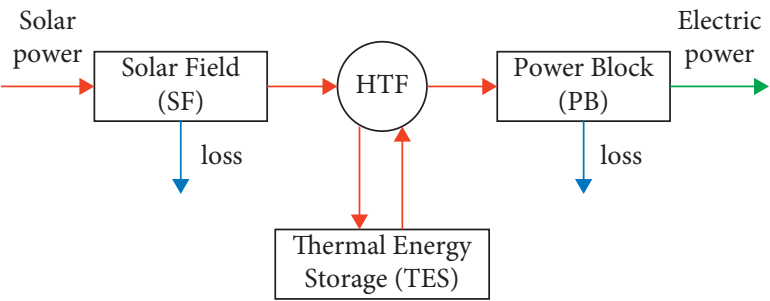

FIgUre 2: Simplified energy flow in CSP plant with TES.

$$
\begin{aligned}
\mathrm{RD}^{\mathrm{ST}} \leq q_{t}^{\mathrm{ST}}-q_{t-1}^{\mathrm{ST}} \leq \mathrm{RU}^{\mathrm{ST}}, \\
0 \leq q_{t}^{\mathrm{ST}} \leq \mathrm{MZ}_{t}, \\
0 \leq q_{t}^{\mathrm{TP}} \leq M\left(1-Z_{t}\right), \\
P_{t}^{\mathrm{SP}}, P_{t}^{\mathrm{TP}}, q_{t}^{\mathrm{TP}}, q_{t}^{\mathrm{SP}}, q_{t}^{\mathrm{ST}} \geq 0 .
\end{aligned}
$$

2.2. Wind Power Model. The cost function of wind power is expressed as follows:

$$
\operatorname{cost}_{t}^{\mathrm{WD}}=k^{\mathrm{WD}} P_{t}^{\mathrm{WD}} \text {. }
$$

The power output by the wind turbines is related to the speed of wind; there is a nonlinear relationship. This relationship can be expressed by a piecewise function [22]. The equation shows the relationship between the power output by a single wind turbine and the speed of wind. When the same model is selected for the wind power generator of the wind farm, the wind farm output can be expressed by equation (19).

$$
\begin{gathered}
P_{\mathrm{var}}(v)=\left\{\begin{array}{cc}
0 & 0 \leq v<v_{i} \\
a+b v^{3} & v_{i} \leq v<v_{r} \\
P_{r} & v_{r} \leq v \leq v_{o} \\
0 & v>v_{o}
\end{array}\right\}, \\
P_{t}^{\mathrm{WD}}=P_{\mathrm{var}}\left(v_{t}\right) N_{L},
\end{gathered}
$$

where

$$
\begin{aligned}
& a=\frac{P_{r} v_{i}^{3}}{v_{i}^{3}-v_{r}^{3}}, \\
& b=\frac{P_{r}}{v_{r}^{3}-v_{i}^{3}} .
\end{aligned}
$$

2.3. Photovoltaic Model. The cost function of wind power is expressed as follows:

$$
\operatorname{cost}_{t}^{\mathrm{PV}}=k^{\mathrm{PV}} P_{t}^{\mathrm{PV}} \text {. }
$$

The photovoltaic power generation model is shown in equations (22) and (23) [5]. Equation (22) expresses that the output power of the photovoltaic power generation is mainly related to the environmental radiation intensity and temperature; equation (23) represents the output power constraint of the photovoltaic power generation.

$$
\begin{aligned}
P_{t}^{\mathrm{PV}} & =\eta^{\mathrm{PV}} S^{\mathrm{PV}} \mathrm{DNI}_{t}\left(1-0.005\left(T_{t}-25\right)\right), \\
P^{\mathrm{PV} \text { min }} & \leq P_{t}^{\mathrm{PV}} \leq P^{\mathrm{PV} \max } .
\end{aligned}
$$

2.4. Thermal Unit Model. The thermal power generator is composed of two parts: operation cost and start-up cost. The operation cost is often described as a quadratic function of the power [33]. Equation (24) represents the total cost of the thermal power units.

$$
\operatorname{cost}_{t}^{G}=\sum_{i=1}^{N}\left(f_{i}\left(P_{t, i}^{G}\right)+S_{i}\left(1-U_{t-1, i}\right)\right) U_{t},
$$

where

$$
f_{i}=a_{i} P_{t, i}^{2}+b_{i} P_{t, i}+c_{i}
$$

Of course, thermal power units must meet relevant constraints during operation. Equation (26) expresses the unit capacity constraint, which dictates that the generator output must be within the maximum and minimum boundaries. Equations (27) and (28) express the unit's start and stop constraints, which dictates that the unit's runs and stops have minimum times. Equation (29) expresses the unit's climbing constraint, which needs to be met by the generator's output power change within the climbing range for each period of time.

$$
\begin{array}{r}
P_{i}^{G \min } \leq P_{t, i}^{G} \leq P_{i}^{G \max }, \\
\left(T_{t-1, i}^{\text {on }}-T_{i}^{\text {on }}\right)\left(U_{t-1, i}-U_{t, i}\right) \geq 0 \\
\left(T_{t-1, i}^{\text {off }}-T_{i}^{\text {off }}\right)\left(U_{t, i}-U_{t-1, i}\right) \geq 0 \\
P_{i}^{G \text { down }} \leq P_{t, i}^{G}-P_{t-1, i}^{G} \leq P_{i}^{G \text { up }} .
\end{array}
$$


2.5. Battery Energy Storage Model. The battery energy storage system model is described as follows [5]. Equations (30) and (31) represent the BES charge and discharge power constraints. Equation (32) expresses the BES state-of-charge constraint. Equation (33) represents the BES dynamic state of charge. The constraint described by equation (34) dictates that the BES cannot be charged and discharged simultaneously.

$$
\begin{aligned}
0 & \leq P_{t}^{\mathrm{ch}} \leq z_{t}^{\mathrm{ch}} P^{\mathrm{ch} \mathrm{max}} \\
0 & \leq P_{t}^{\mathrm{disch}} \leq z_{t}^{\mathrm{disch}} P^{\mathrm{disch} \max }, \\
\mathrm{SOC}^{\mathrm{min}} & \leq \mathrm{SOC}_{t} \leq \mathrm{SOC}^{\mathrm{max}}, \\
\mathrm{SOC}_{t} & =\mathrm{SOC}_{t-1}+\Delta t\left(\frac{\eta^{\mathrm{ch}} P_{t}^{\mathrm{ch}}}{E_{m}}-\frac{P_{t}^{\mathrm{disch}}}{\eta^{\mathrm{disch}} E_{m}}\right), \\
z_{t}^{\mathrm{ch}}+z_{t}^{\mathrm{disch}} & \leq 1 .
\end{aligned}
$$

2.6. Demand Response Model. Applying the demand response method can make the user-side elastic load a participant in the power market dispatch. This paper adopts the price-based demand response (PBDR) [13]. PBDR achieves the purpose of smoothing the load curve by using the timeof-use electricity price method. The load demand after applying PBDR is calculated as follows.

Define the electricity price elasticity $e_{s t}$ according to the demand principle of economics,

$$
\left\{\begin{array}{l}
e_{s t}=\frac{\Delta L_{s} / L_{s}^{0}}{\Delta P_{t} / P_{t}^{0}} \\
e_{s t} \leq 0, \quad s=t, \\
e_{s t} \leq 0, \quad s \neq 0,
\end{array}\right.
$$

where $e_{s t}$ represents the price elasticity from time $s$ to time $t$. $L_{s}^{0}, P_{t}^{0}$ are the electricity load at time $s$ and the electricity price at time $t$, before PBDR. $\Delta L_{s}, \Delta P_{t}$ are the load and price fluctuations at times $s$ and $t$, after PBDR.

Define the value of consumption $L_{t}$ as $V\left(L_{t}\right)$ and the net profit of the users' consumption of electricity as $\pi^{p}$,

$$
\pi^{p}=V\left(L_{t}\right)-L_{t} P_{t}
$$

Find the first and second derivatives of formula (36) with respect to $P_{t}$, and perform Taylor expansion of $V\left(L_{t}\right)$,

$$
\begin{aligned}
V\left(L_{t}\right) & =V\left(L_{t}^{0}\right)+\frac{\partial V\left(L_{t}\right)}{\partial L_{t}}\left[L_{t}-L_{t}^{0}\right]+\frac{1}{2} \frac{\partial^{2} V\left(L_{t}\right)}{\partial\left(L_{t}\right)^{2}}\left[L_{t}-L_{t}^{0}\right]^{2} \\
& =V\left(L_{t}^{0}\right)+P^{0}\left[L_{t}-L_{t}^{0}\right]\left\{1+\frac{1}{2} \frac{\left[L_{t}-L_{t}^{0}\right]}{e_{t t} L_{t}^{0}}\right\} .
\end{aligned}
$$

Substituting formula (37) into formula (36), the initial model of PBDR can be obtained,

$$
L_{t}=L_{t}^{0} \times\left\{1+e_{t t} \frac{L_{t}-L_{t}^{0}}{L_{t}^{0}}\right\} .
$$

Equation (38) is the load demand after ignoring the influence of elasticity $e_{t t}$ at time $t$. Add the load demand of the cross-heterogeneity $e_{s t}$ to get the final model,

$$
L_{t}=L_{t}^{0} \times\left\{1+e_{t t} \frac{L_{t}-L_{t}^{0}}{L_{t}^{0}}+\sum_{\substack{t=1 \\ s \neq t}}^{24} e_{s t} \frac{P_{t}-P_{t}^{0}}{P_{t}^{0}}\right\} .
$$

2.7. Power Balance Constraint. The output of all the generation sides in the model should meet the load requirements. The constraint relationship is shown in equation (36).

$$
P_{t}^{\mathrm{CSP}}+P_{t}^{\mathrm{WD}}+P_{t}^{\mathrm{PV}}+P_{t}^{\mathrm{BES}}+\sum_{i=1}^{N} P_{t, i}^{G} \geq P_{t}^{D} .
$$

\section{Case Study and Simulation}

This paper provides a mathematical model of the system in Section 2. The simulation system in this paper includes a CSP station with a heat storage system, a wind farm, a photovoltaic power station, and ten thermal power units. The load and environmental parameters are taken from an area in Gansu Province and the wind and DNI data are taken from China Meteorological Station. The parameters of the units come from relevant references. The simulation running time of the system is from 0 o'clock to 24 o'clock, and hour is taken as the scheduling unit. The design of the following 4 cases will be simulated and analyzed in this section; among those cases, wind power and photovoltaic are defined as nonschedulable renewable energy generating units:

(i) Case 1: equipped with conventional thermal power generating sets and nonschedulable renewable energy generating units

(ii) Case 2: considering the demand response to be equipped with conventional thermal power generating units and nonschedulable renewable energy generating units

(iii) Case 3: considering the demand response to be equipped with conventional thermal power units, nonschedulable renewable energy generating units, and battery energy storage

(iv) Case 4: considering the demand response to be equipped with conventional thermal power units, nonschedulable renewable energy generating units, battery energy storage, and concentrating solar power plants

The proposed model can be described as an MINLP model, which is solved by calling the CPLEX solver, through 


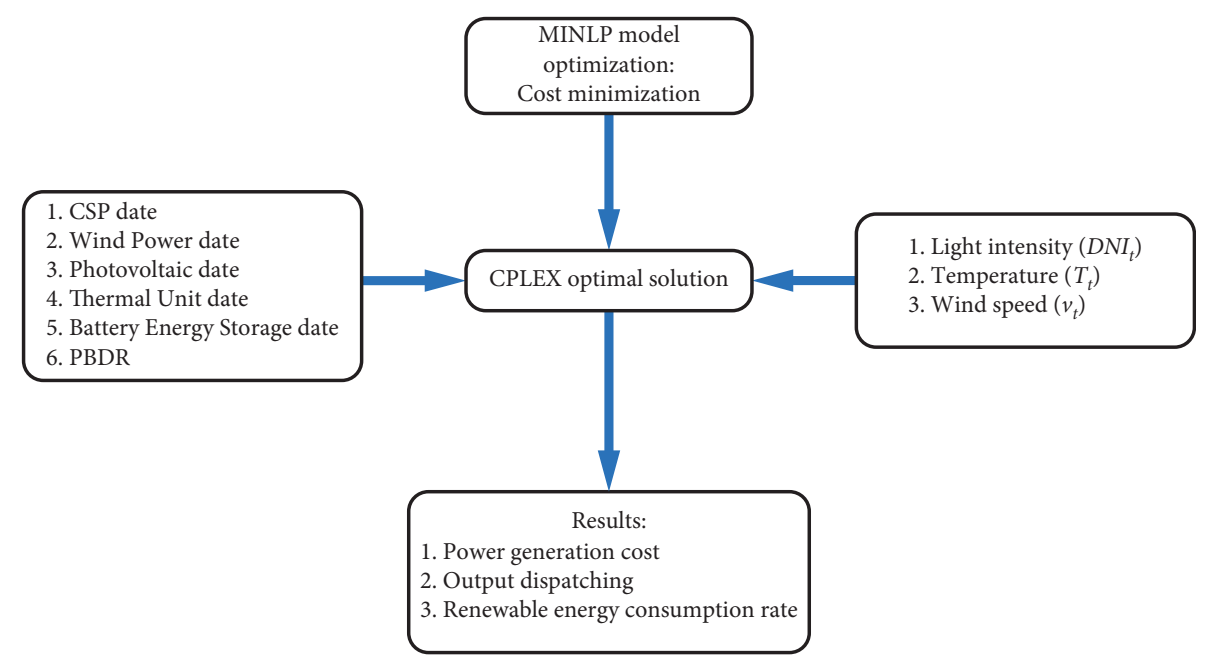

Figure 3: Schematic of the solution process.

the YALMIP platform in MATLAB. The solution process is shown in Figure 3.

3.1. Parameter Setting. Table 1 shows the parameters of conventional thermal power units [33]. Table 2 shows the parameters of the CSP plant. Table 3 shows the parameters of a single wind turbine. Table 4 shows the parameters of the photovoltaic power units [9]. Table 5 shows the parameters of the battery energy storage station [15]. For the demand response parameters, refer to [32]. Figure 4 shows the original load demand curve. Figure 5 shows the predicted wind power generation and the predicted photovoltaic power.

3.2. Results and Analysis. This section presents the simulation results of the four cases in addition to an analysis of the results based on the comparison results.

3.2.1. Four Cases of Unit Output. This section presents four cases of the arrangements and costs output by the unit. Figure 6 shows the output of Case 1. Figure 7 shows the output arrangement of Case 2. Figure 8 shows the output arrangement of Case 3. Figure 9 shows the output arrangement of Case 4. Finally, Table 6 shows the cost of the system's power generation.

It can be seen from Table 6 that the addition of a nonenergy storage renewable energy generation system not only increases the cost of thermal power generation but also increases the total power generation cost. However, after joining the BES and the CSP plant, the cost of the system's power generation has been reduced. In particular, the addition of the CSP plant has significantly reduced the total cost, the unit cost of the thermal power generation, and the total power generation cost of the system. By analyzing Figures 6-9, first, with PBDR and the addition of BES and the CSP plants to the power system, there is a gradual increase in wind power consumption. Still, it has little impact on the photovoltaic power system. Second, BES is not sensitive to the renewable energy generation system by itself, but the BES becomes more active after the addition of the CSP plant. Third, from the output of thermal power generation, it can be seen that the renewable energy generation system can effectively assume the role of peak regulation after the addition of the CSP plant. Therefore, the following text will conduct a more specific analysis of the thermal power generation and other renewable energy generation systems, especially wind power generated from the CSP plant.

\subsubsection{The Impact of the CSP Plant on the Thermal Power} Generation. In this paper, the total load of the system minus the surplus of the renewable energy generation is called the equivalent load. Figure 10 shows identical load conditions in the four cases.

It can be seen from Figure 10 that the application of PBDR to the original load can effectively cut the peak of the original load, but the effect of the valley filling is not obvious. From comparing Cases 1-3 and after applying PBDR, the daytime peak of the equivalent load is significantly weakened, but it shows no sensitivity to the evening peak. The equivalent load has undergone almost no change after BES is put into operation. It can be seen from the curve of Case 4 that the addition of the CSP plant has a more significant impact on the fluctuation of the equivalent load, and the peak of equivalent load is reduced significantly; at the same time, the trough is reduced. Table 7 shows the specific relevant parameters of the equivalent load in different cases.

It can be seen from the data in Table 7 that the addition of the CSP plant greatly weakens the peaks and the valleys, while the renewable energy generation system without the CSP plant has no significant difference in the maximum peak-valley difference of the equivalent load. The equivalent load variance can represent the fluctuation of the load. Due to the uncertainty of its output, the renewable energy generation system without CSP increases the equivalent load fluctuation. The addition of the CSP plant can effectively reduce the fluctuation of the equivalent load. The above problems will directly affect the related costs of thermal 
TABLE 1: The parameters of the thermal power units.

\begin{tabular}{lcccccccccc}
\hline Unit & $P_{\max }(\mathrm{MW})$ & $P_{\min }(\mathrm{MW})$ & $a\left(\$ / \mathrm{MW}^{2} \mathrm{~h}\right)$ & $b(\$ / \mathrm{MWh})$ & $c(\$ / \mathrm{h})$ & $T_{\text {off }}(\mathrm{h})$ & $T_{\text {on }}(\mathrm{h})$ & $S(\$ / \mathrm{h})$ & $\mathrm{RU}(\mathrm{MW} / \mathrm{h})$ & $\mathrm{RD}(\mathrm{MW} / \mathrm{h})$ \\
\hline 1 & 130 & 20 & 0.00200 & 16.60 & 700 & 5 & 5 & 1100 & 130 \\
2 & 130 & 20 & 0.00211 & 16.50 & 680 & 5 & 5 & 1120 & 130 & 130 \\
3 & 85 & 25 & 0.00790 & 22.74 & 480 & 3 & 3 & 520 & 80 & 80 \\
4 & 80 & 20 & 0.00712 & 22.26 & 370 & 3 & 3 & 340 & 80 & 80 \\
5 & 55 & 10 & 0.00413 & 25.92 & 660 & 1 & 1 & 60 & 55 & 55 \\
6 & 55 & 10 & 0.00222 & 27.27 & 665 & 1 & 1 & 60 & 55 \\
7 & 55 & 10 & 0.00173 & 27.29 & 670 & 1 & 1 & 60 & 55 & 55 \\
\hline
\end{tabular}

TABLE 2: The parameters of the CSP plant.

\begin{tabular}{lc}
\hline Parameter & Value \\
\hline$P^{\text {CSPmax }}(\mathrm{MW})$ & 100 \\
$P^{\text {CSPmin }}(\mathrm{MW})$ & 10 \\
$q^{\text {TESmax }}(\mathrm{MWh})$ & 1000 \\
$q^{\text {TESmin }}(\mathrm{MWh})$ & 100 \\
$P^{\text {climmax }}(\mathrm{MW} / \mathrm{h})$ & 70 \\
$P^{\text {charmax }}(\mathrm{MW} / \mathrm{h})$ & 300 \\
$\eta_{1}$ & 0.45 \\
$\eta_{2}$ & 0.51 \\
\hline
\end{tabular}

TABLE 3: The parameters of a single wind turbine.

\begin{tabular}{lcccc}
\hline$P_{r}(\mathrm{MW})$ & $V_{i}(\mathrm{~m} / \mathrm{s})$ & $V_{r}(\mathrm{~m} / \mathrm{s})$ & $V_{o}(\mathrm{~m} / \mathrm{s})$ & $k^{\mathrm{WD}}(\$ / \mathrm{MWh})$ \\
\hline 2400 & 2 & 14 & 25 & 24 \\
\hline
\end{tabular}

TABle 4: The parameters of the photovoltaic units.

\begin{tabular}{llcc}
\hline $\mathrm{P}^{\mathrm{PV} m a x}(\mathrm{MW})$ & $\eta^{\mathrm{PV}}$ & $S^{\mathrm{PV}}\left(\mathrm{m}^{2}\right)$ & $k^{\mathrm{PV}}(\$ / \mathrm{MWh})$ \\
\hline 100 & 15.7 & 21000 & 21 \\
\hline
\end{tabular}

TABLE 5: The parameters of the battery energy storage station.

\begin{tabular}{lcccc}
\hline$E_{\text {max }}(\mathrm{MWh})$ & $P_{\text {chmax }}(\mathrm{MW})$ & $P_{\text {dischmax }}(\mathrm{MW})$ & $\eta^{\text {ch }}$ & $\eta^{\text {disch }}$ \\
\hline 50 & 10 & 10 & 0.9 & 0.9 \\
\hline
\end{tabular}

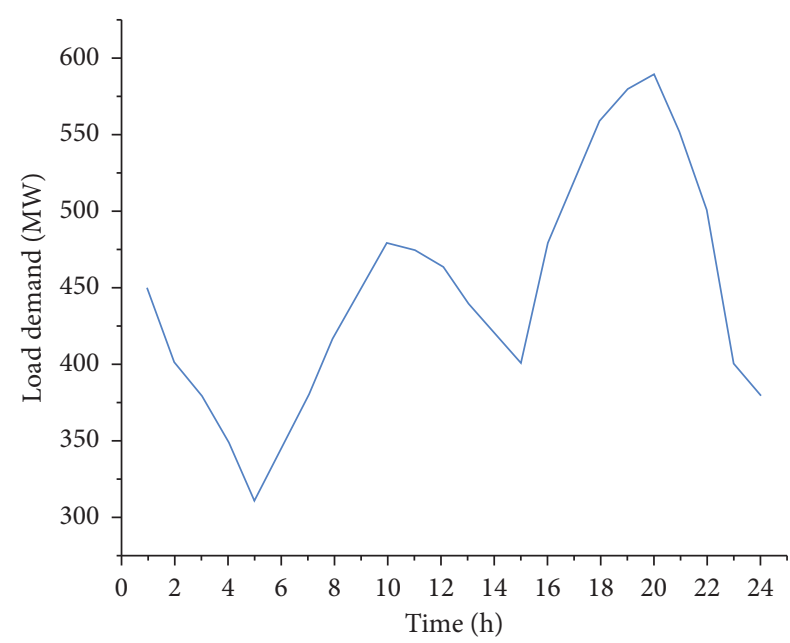

FIgUre 4: The original load demand.

power generation. Table 8 shows the cost parameters of the thermal power generation in different cases.

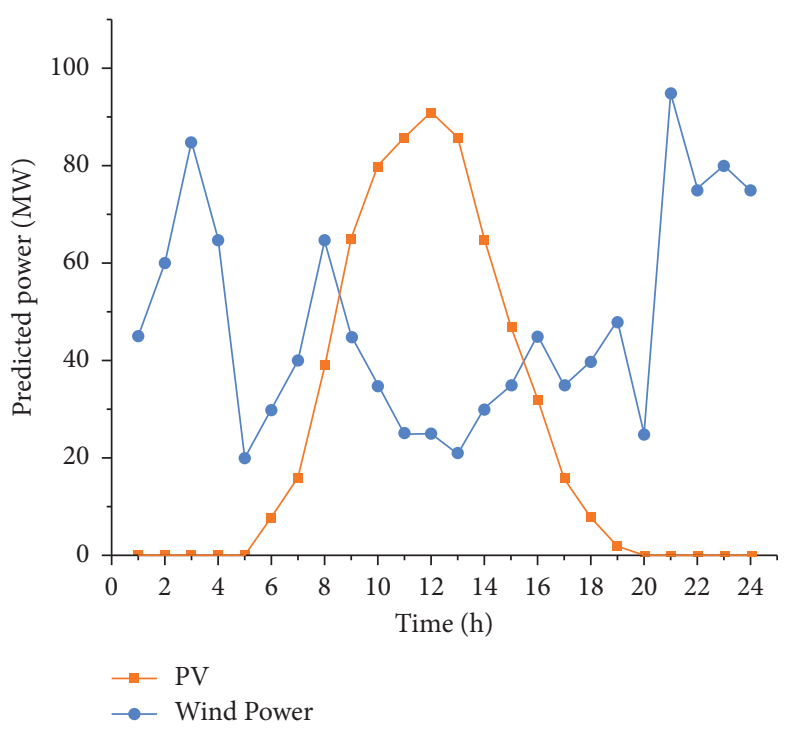

FIgURE 5: Day-ahead predicted power.

The original case in Table 8 refers to when the thermal power unit bears all the load. The start-up cost reflects the impact of the uncertainty of the renewable energy system on the dispatch of the thermal power units. The addition of the CSP plant effectively reduces the negative effects of the renewable energy generation systems on the traditional thermal power generation; as the load of the thermal power units decreases, the cost of the peak shaving is transferred to the renewable energy generation system, which effectively reduces the thermal power unit generation cost.

3.2.3. The Impact of the CSP Plant on Wind Power Generation. Among renewable energy generation systems, wind power generation systems suffer the most from randomness. Figure 11 shows the comparison between wind power consumption and abandonment power in the four cases. Table 9 shows the specific wind power consumption and the abandonment data.

The consumption rate of wind power in Case 4 (Figure 11(a)) is significantly higher than that of the other cases. From the curve in Figure 11, it can be seen that the wind power consumption rate of Case 4 is higher than that of other cases almost all day, especially in the time period of 9-13 o'clock; Case 4 in Figure 11(b) has only a partial wind abandonment phenomenon during the early stages. Furthermore, the data in Table 9 show that the addition of the CSP plant reduces the curtailment rate of wind power to 


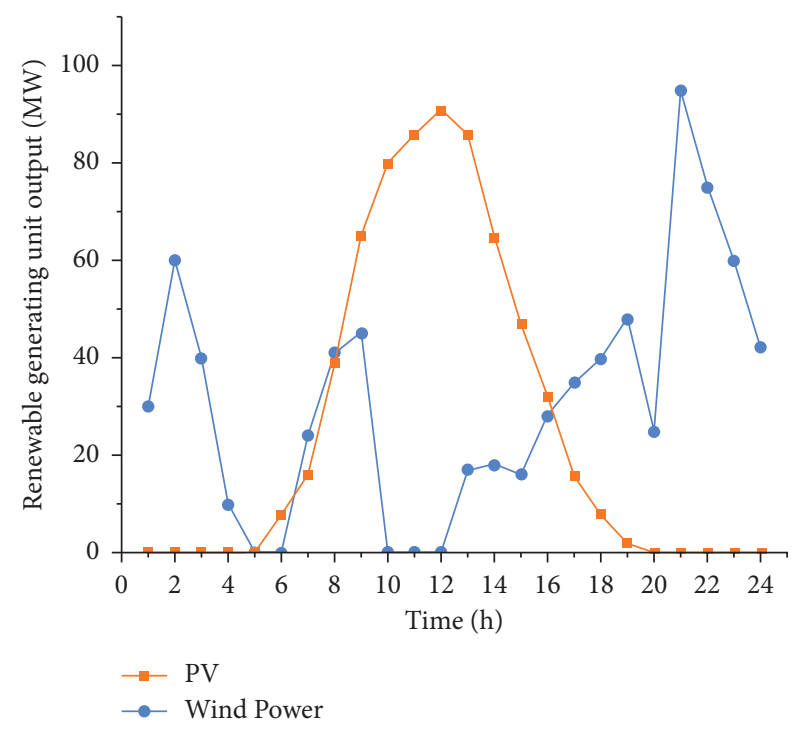

(a)

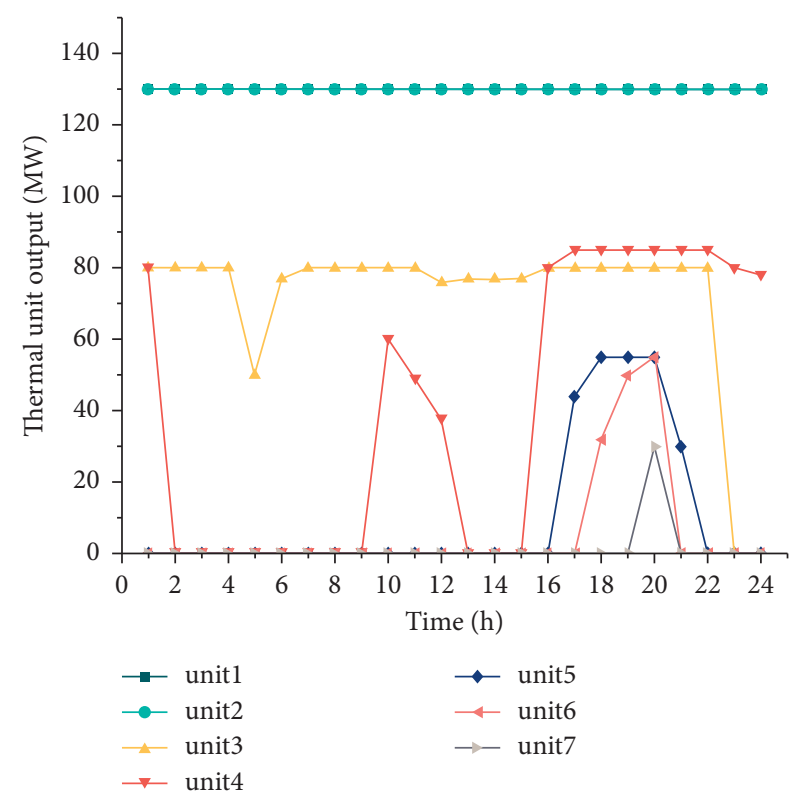

(b)

Figure 6: The output of Case 1: (a) output of renewable energy generating unit; (b) output of thermal unit.

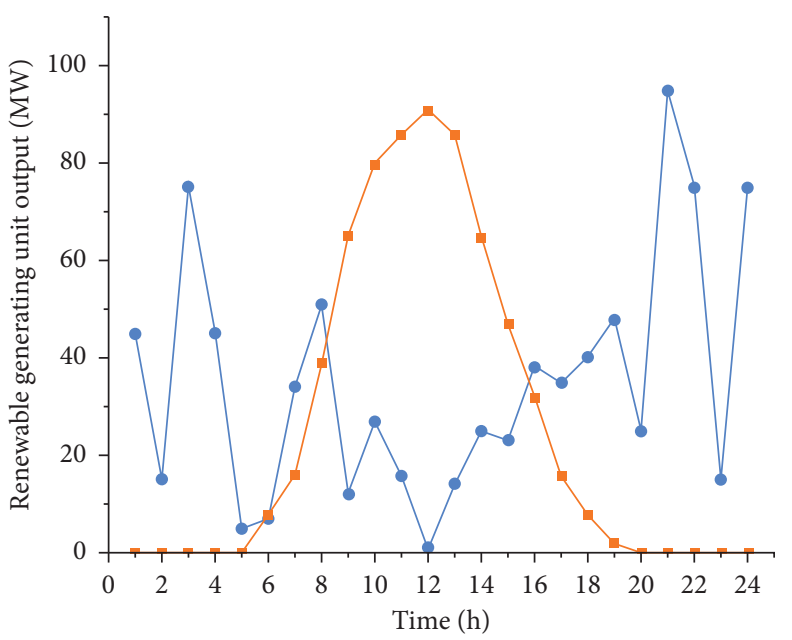

$\rightarrow \mathrm{PV}$

- Wind Power

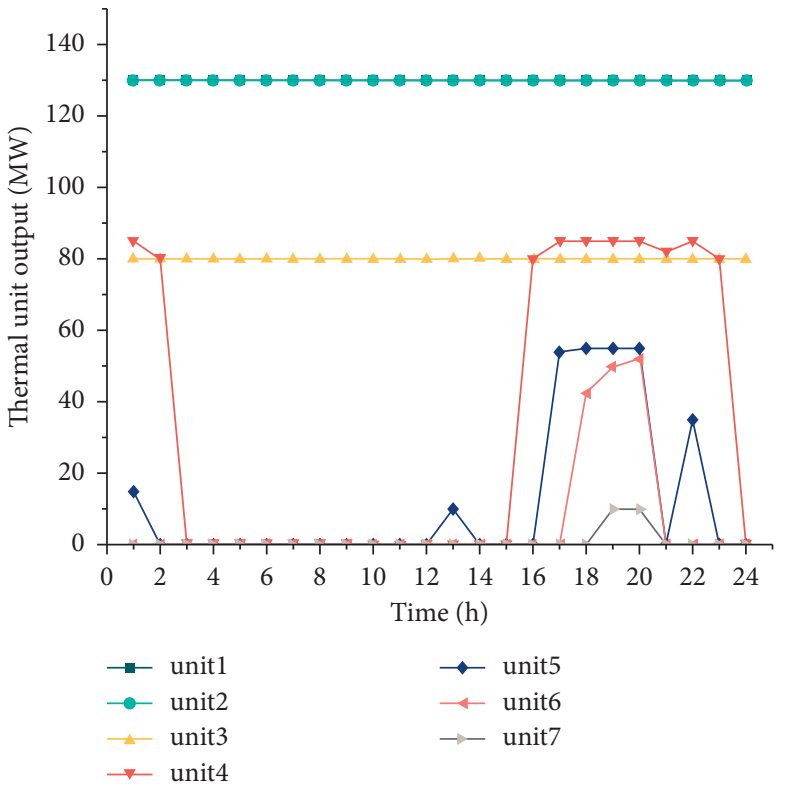

(b)

Figure 7: The output of Case 2: (a) output of renewable energy generating unit; (b) output of thermal unit.

7.34\%. The addition of the CSP plant has significantly better wind power absorption effects than the other taken measures. For further analyses of the reasons for abandonment and the role the CSP plant plays, Figure 12 shows the output of the thermal power units after all the renewable energy generation power is used in Case 3.

From the comparison between Figures 12 and 8(b), it can be seen that when wind power is absorbed, the mainly affected output is that of unit 3 . Figure 13 shows the cost function of thermal power unit 3 , which is related to the output of the unit and the number of unit start-ups.

It can be seen from Figure 13 that the number of startups has no noticeable impact on the power generation cost of unit 3 under the condition of the entire load operation. Still, the unit's output has a greater effect on its cost, which increases the power generation cost of the unit when the output is unstable. Therefore, there is a large number of wind abandonment situations in Case 3. The addition of the CSP 


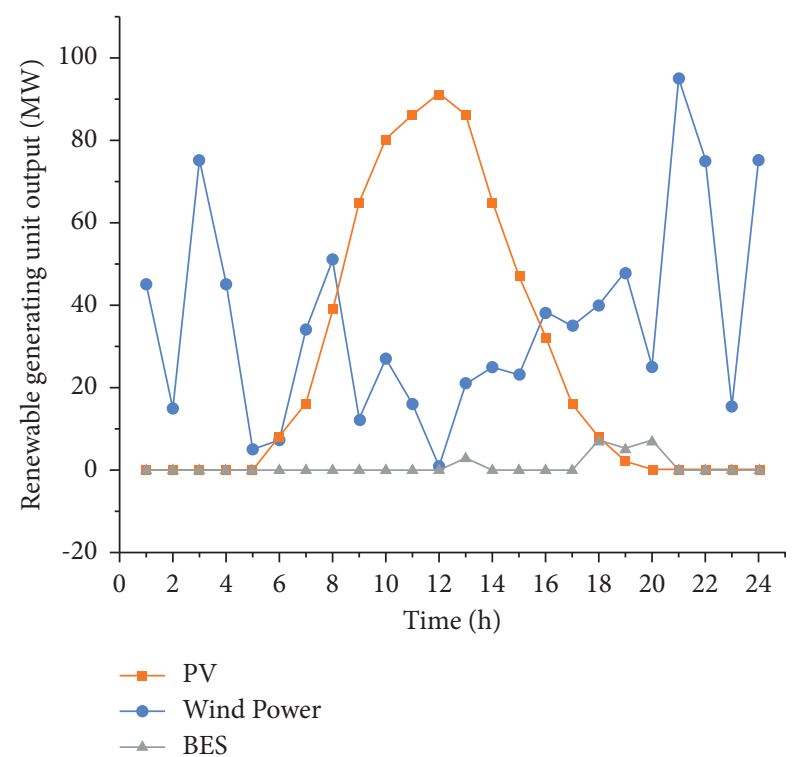

(a)

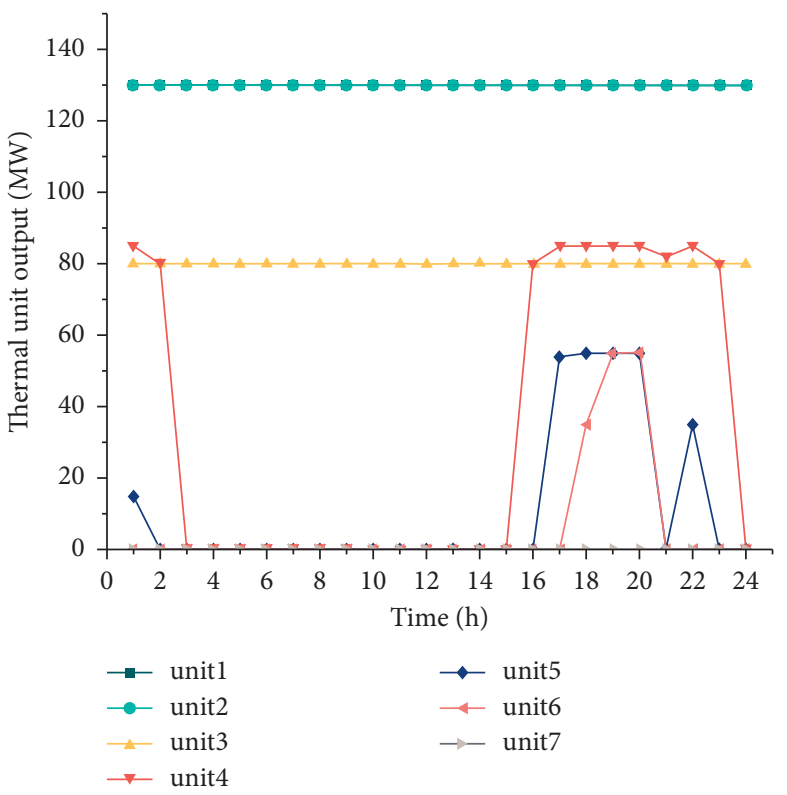

(b)

Figure 8: The output of Case 3: (a) output of renewable energy generating unit; (b) output of thermal unit.

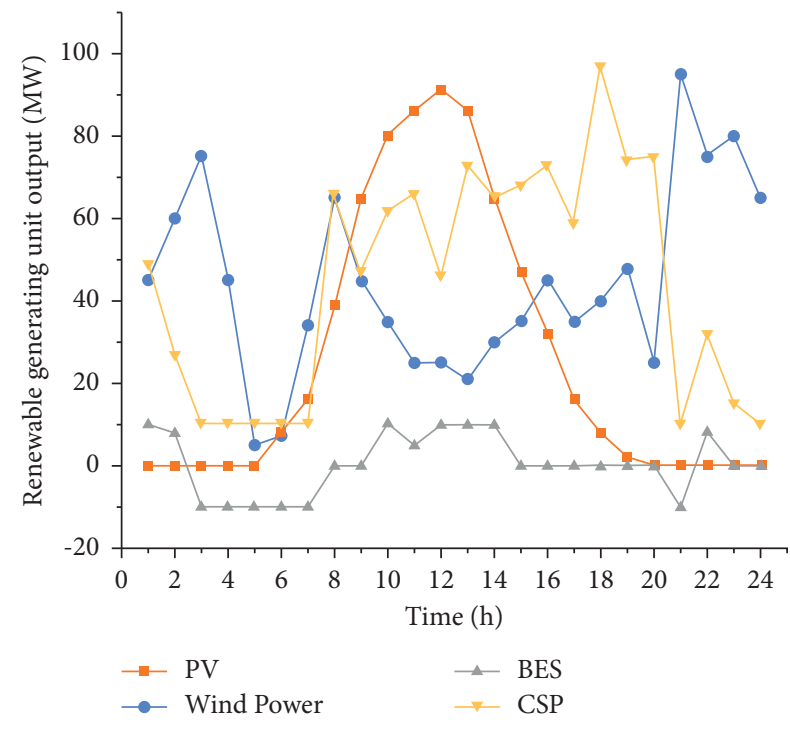

(a)

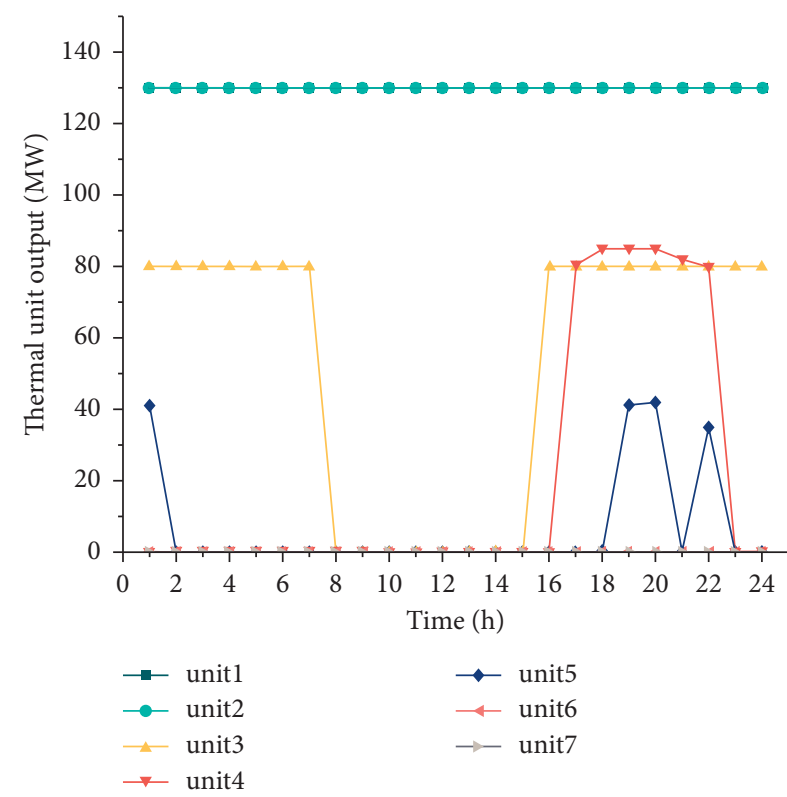

(b)

FIGURE 9: The output of Case 4: (a) output of renewable energy generating unit; (b) output of thermal unit.

TABLE 6: The cost of the system's power generation.

\begin{tabular}{lccccc}
\hline Case & Thermal power cost $(\$)$ & PV cost $(\$)$ & Wind power $(\$)$ & CSP cost $(\$)$ & - \\
\hline 1 & 235409.65 & 13461 & 17976 & - & 266846.65 \\
2 & 238732.21 & 13461 & 20184 & - & 272377.21 \\
3 & 235824.40 & 13461 & 20352 & 26536 \\
4 & 196457.15 & 13461 & 25400 & 2637.40 \\
\hline
\end{tabular}




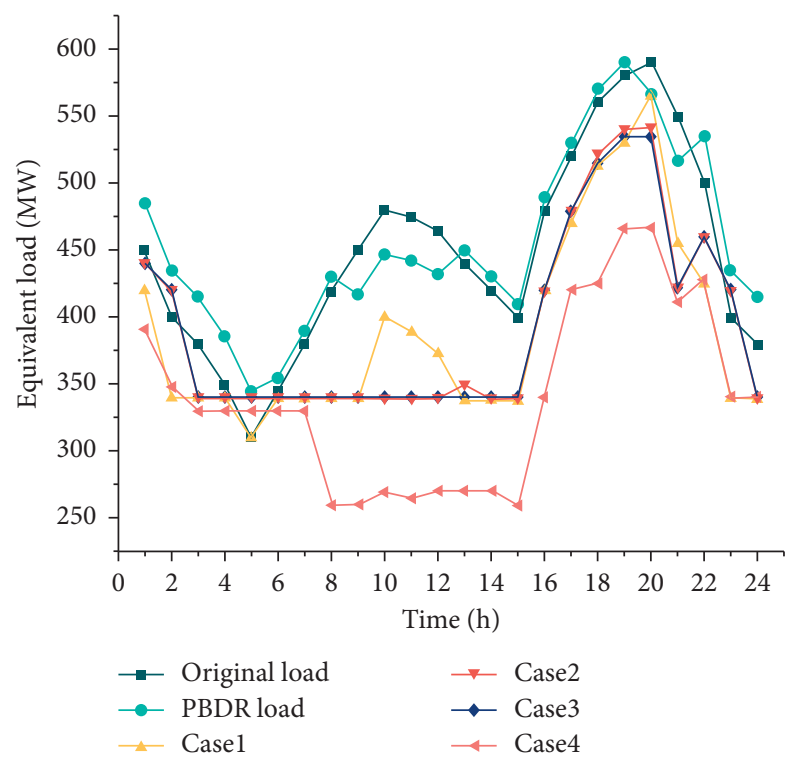

FIgUre 10: Identical load conditions in the different cases.

TABLE 7: The specific relevant parameters of the equivalent load in different cases.

\begin{tabular}{lcccc}
\hline Case & Peak (MW) & Valley (MW) & Maximum peak-valley difference (MW) & Equivalent load mean square error \\
\hline Original load & 590 & 310 & 270 & 5547.526 \\
PBDR load & 590 & 345 & 245 & 4279.9427 \\
1 & 565 & 310 & 255 & 4865 \\
2 & 542 & 340 & 202 & 4830 \\
3 & 535 & 340 & 195 & 4651 \\
4 & 467 & 260 & 207 & 4422 \\
\hline
\end{tabular}

TABLE 8: The cost parameters of the thermal power generation in different cases.

\begin{tabular}{lccccc}
\hline Case & Operating costs $(\$)$ & Start-up cost $(\$)$ & Total cost $(\$)$ & Total power generation $(\mathrm{MW})$ & Unit power generation cost $(\$)$ \\
\hline Original & 280841.44 & 3380 & 284221.44 & 10725 & 26.50 \\
1 & 231109.65 & 4300 & 235409.65 & 9335 & 25.22 \\
2 & 234772.21 & 3960 & 238732.21 & 9435 & 25.30 \\
3 & 231984.40 & 3840 & 235824.40 & 9406 & 25.07 \\
4 & 192917.15 & 3540 & 196457.15 & 8141 & 24.13 \\
\hline
\end{tabular}

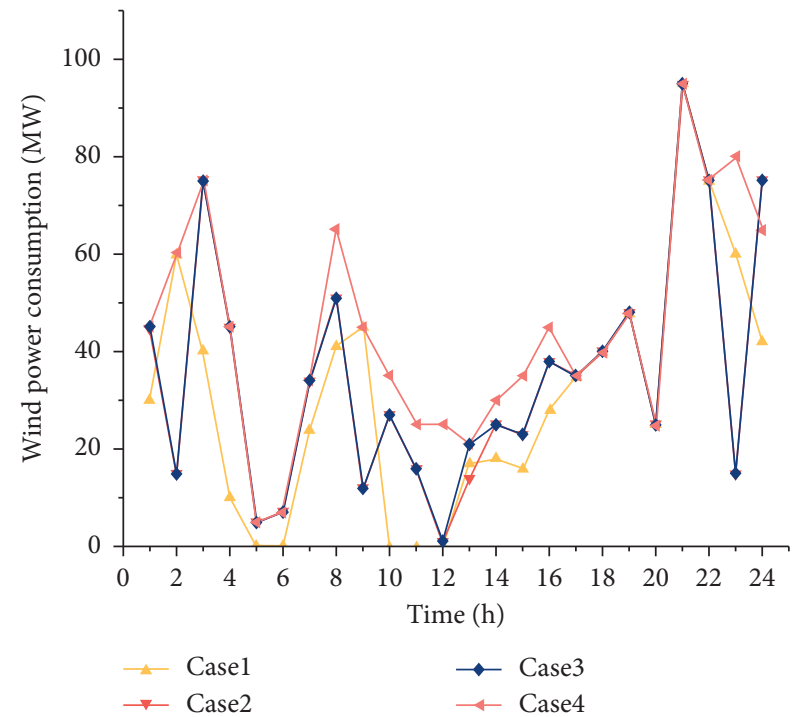

(a)

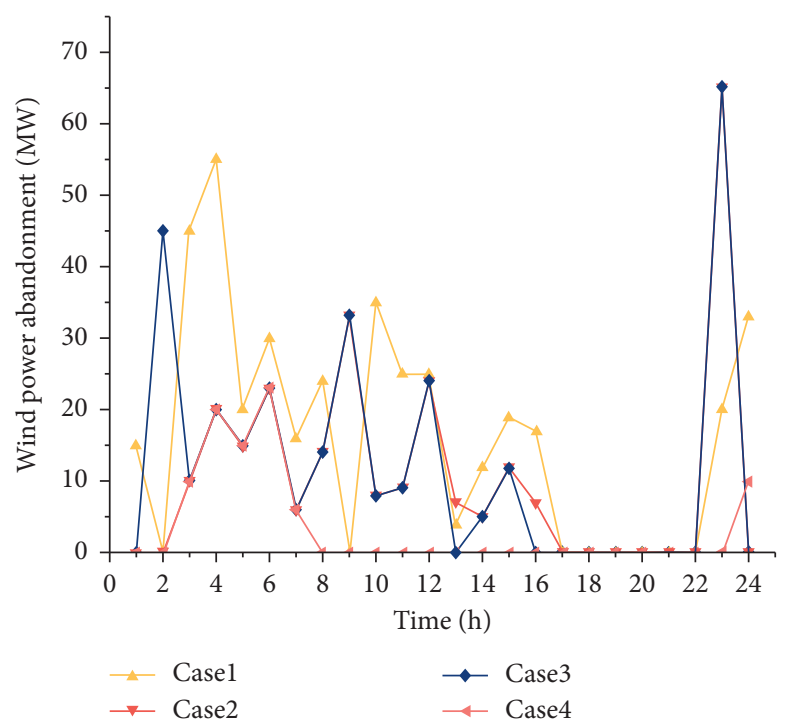

(b)

Figure 11: Wind power output in different cases: (a) wind power consumption; (b) wind power abandonment. 
TABLE 9: Wind power consumption and abandonment in different cases.

\begin{tabular}{lccc}
\hline Case & Total consumption power $(\mathrm{MW})$ & Total abandonment power $(\mathrm{MW})$ & Wind curtailment rate $(\%)$ \\
\hline 1 & 749 & 395 & 34.53 \\
2 & 841 & 303 & 26.49 \\
3 & 848 & 289 & 25.42 \\
4 & 1060 & 84 & 7.34 \\
\hline
\end{tabular}

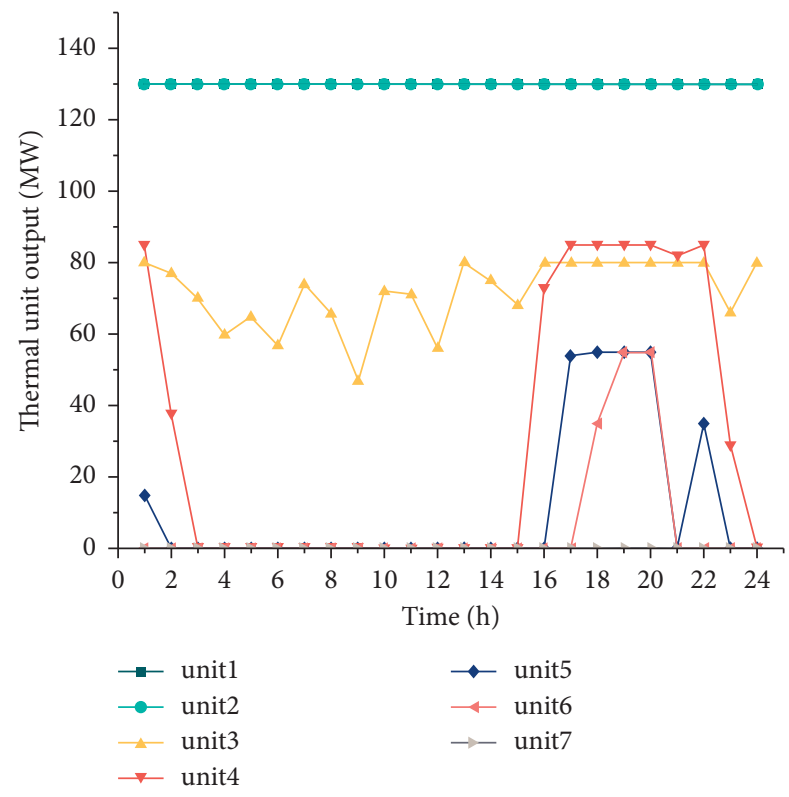

FIgURE 12: The thermal unit output of Case 3 in wind power consumption fully.

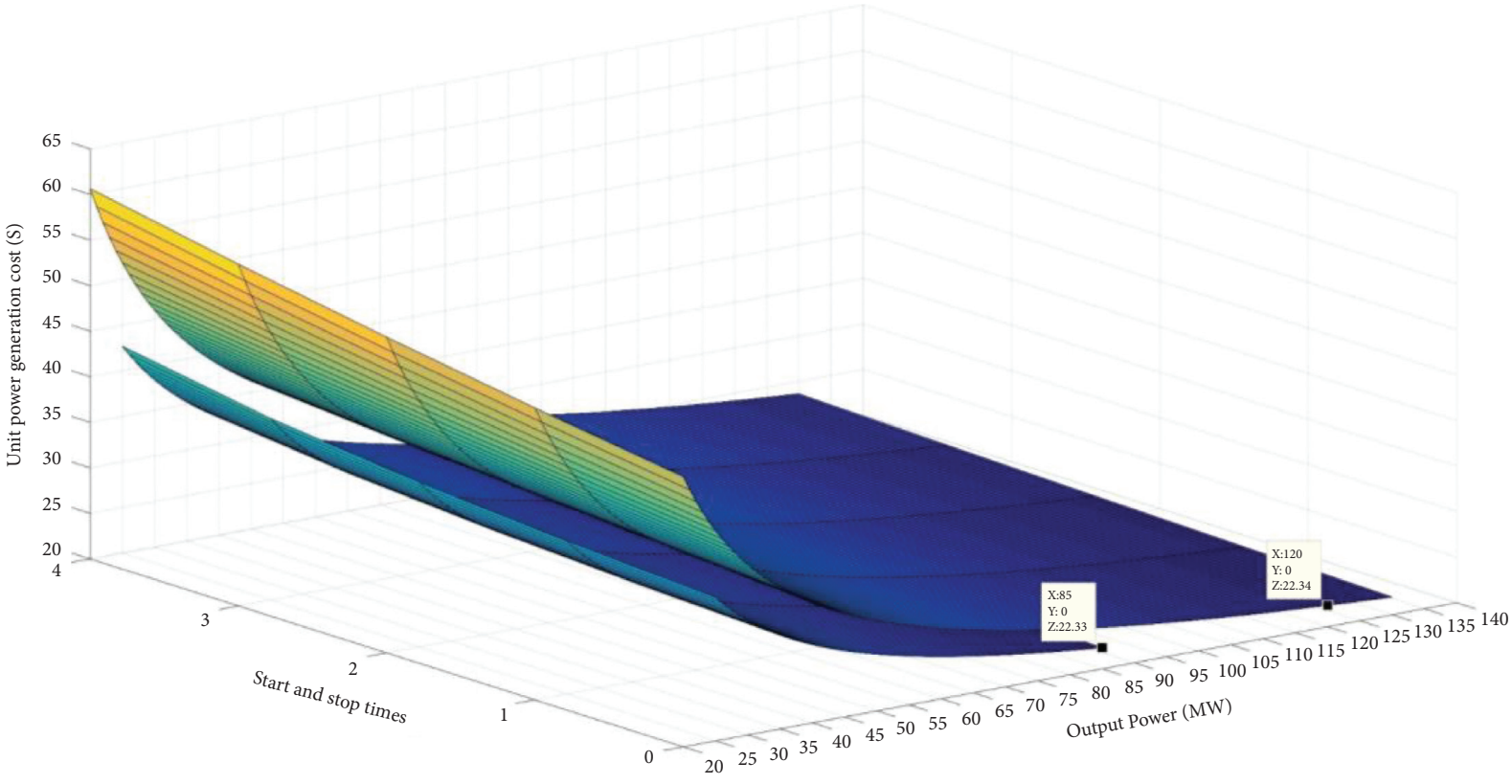

Figure 13: The cost function of thermal power units 1 and 3.

plant ensures the stable operation of the thermal power units in high wind power consumption rate; it transfers the peakshaving pressure to the CSP unit, thus guaranteeing the wind power consumption rate and reducing the cost of the thermal power generation. At the same time, it can be seen from the figure that the unit power generation cost is reduced with the increase of the output power, regardless of the number of units. And the unit power generation cost of unit 1 with a large capacity is higher than that of unit 3 when the output power is low. When unit 1 is running at full load, 
its cost is less than the minimum power generation cost of unit 3. It can be seen from the relevant data of the thermal power units and the power generation cost function that the large-capacity units are characterized by low full-load operation costs and high start-up costs. In contrast, the smallcapacity units have relatively high operating costs but low start-up costs. Therefore, the large-capacity units are often responsible for the base load, while the small-capacity units are responsible for the peak shaving.

\section{Conclusions}

This paper studies the day-ahead scheduling problems of the CSP plant, the wind power generation system, the photovoltaic system, the battery energy storage system, and the conventional thermal power plants. The system schedule is solved by optimizing the cost target and the CPLEX solver is called in the YALMIP environment to obtain the optimal solution. This paper studies and compares the role of the CSP plant in the renewable energy generation system in four cases. The results show that when the CSP plant is added to the renewable energy generation system, the total system cost is at its lowest, 260,894.15 USD. The unit thermal power cost has also been reduced to $24.13 \$ / \mathrm{MWh}$.

Furthermore, when the CSP plant is added, it has a significant peak-shaving effect on the equivalent load and the equivalent load fluctuation is minimal. The phenomenon of wind curtailment has been significantly reduced; the wind curtailment rate has been reduced from $25.42 \%$ to $7.34 \%$. The proportion of renewable energy consumption has increased significantly. The results also show that a single addition of a battery energy storage power station on the generation side of a renewable energy generation system, without CSP, has no obvious effect on promoting renewable energy generation and consumption. Compared to the scale of renewable energy generation, the small scale of the battery energy storage power stations cannot meet the requirements of the uncertain large-scale renewable energy generation storage. The large-scale increase in the battery energy storage power stations requires higher costs. When the thermal power unit that bears the basic load does not have to start and stop, its power generation cost is lower. When the renewable energy power access brings the start-up cost, a large amount of wind power abandonment often occurs at this time. The dispatch of a renewable energy cogeneration output through the CSP plant transfers the start-up cost of the thermal power generation. It reduces the impact of uncertain renewable energy generation on thermal power generation. Therefore, the main restrictions on renewable energy generation have been lifted and the consumption rate of renewable energy generation has been increased.

The CSP plant is an indispensable link in future highproportion renewable energy generation systems. By optimizing the dispatch of the CSP plant and the reasonable configuration of the energy storage system, the stability of the system can be greatly improved; the consumption of renewable energy generation can be promoted. The cost of the thermal power generation and that of the comprehensive power generation can also be reduced. Future work will try to do a further improvement upon the system's model, taking into consideration both the cogeneration model and the system's profit; the exploration of the potential of solar thermal power generation systems is also a part of our future work.

\section{Nomenclature}

Indies

$i$ : Index of thermal unit

$t$ : Index of time periods (h).

\section{Parameters and Constants}

$k^{\mathrm{CSP}}: \quad$ Cost factor of the CSP unit power

$k^{\mathrm{WD}}$ :

$k^{\mathrm{PV}}:$ generation (\$/MWh) Cost factor of the wind power generation (\$/MWh)

$e_{t t}: \quad$ Matrix of price elasticity

$\eta_{1}$ : $\quad$ Efficiency on thermoelectricity conversion coming from the SF (\%)

$\eta_{2}$ : $\quad$ Efficiency on thermoelectricity conversion coming from the SF (\%)

$\eta^{\mathrm{PV}}: \quad$ Efficiency on photoelectric conversion of photovoltaic (\%)

$a_{i}, b_{i}$, and $c_{i}$ : Cost function coefficients of the $i$ th conventional thermal unit

$\eta^{c h}$ and $\eta^{\text {disch: }}$ Efficiency of the BES charge and discharge (\%)

$v_{t}: \quad$ Wind speed at period $t(\mathrm{~m} / \mathrm{s})$

$\mathrm{DNI}_{t}: \quad \quad$ Radiation intensity at time $t\left(\mathrm{~kW} / \mathrm{m}^{2}\right)$

$E_{m}: \quad$ Capacity of the BES (MWh)

$L_{t}^{0}$ and $L_{t}$ : $\quad$ Electricity demand of before and after demand response (MW)

M: $\quad$ Capacity of the TES charge and discharge (MW)

$N_{L}$ : Number of wind turbines in wind farm

$P_{r}: \quad$ Rated power of a wind turbine

$P_{t}^{D}: \quad$ Electricity demand at period $t$

$P^{\mathrm{PV} m i n}$ and $\quad$ Capacity of the PV unit (MW)

$P^{\text {PV max }}$

$P_{i}^{G \min }$ and Lower and upper bound of the electricity

$P_{i}^{G \max }$ :

$P_{i}^{i}$ down and

$P_{i}^{G \text { up }}$

$P^{\text {ch max }}$ and

$P^{\text {disch max }}$

$P^{\text {CSP min }}$ and $P^{\text {CSP max. }}$

$P_{s}^{0}$ and $P_{s}$ : produced by the $i$ th thermal unit (MW) Ramp-down and ramp-up of the $i$ th thermal unit $(\mathrm{MW} / \mathrm{h})$

Maximum capacity of the BES charge and discharge (MW)

Capacity of the CSP unit (MW)

response $(\$)$

$P^{\text {clim max }}$ : Maximum climbing power $(\mathrm{MW} / \mathrm{h})$

$P^{\text {charmax }}$ The TES maximum charging and discharging power $(\mathrm{MW} / \mathrm{h})$ 


$q^{\mathrm{PB} \text { min }}$ and
$q^{\mathrm{PB} \max }:$
$q^{\mathrm{SP} \text { min }}$ and
$q^{\mathrm{SP} \max }:$
$q^{\mathrm{TES} \min }$ and
$q^{\mathrm{TES} \max }:$
$\mathrm{RD}^{\mathrm{TP}}$ and
$\mathrm{RU}^{\mathrm{TP}}:$
$\mathrm{RD}^{\mathrm{ST}}$ and
$\mathrm{RU}^{\mathrm{ST}}:$
$S^{\mathrm{PV}}:$
$S_{t, i}:$
$\mathrm{SOC}^{\mathrm{min}}$ and
$\mathrm{SOC}^{\mathrm{max}}:$
$T_{t}:$
$T_{i}^{\text {on }}:$
$T_{i}^{\text {off }}:$

Minimum and maximum acceptable capacity of the CSP unit (MWt) Minimum and maximum acceptable capacity of the SF to the CSP unit (MWt) Minimum and maximum thermal energy level of the TES (MWht) Ramp-down and ramp-up rate of the TES charge $(\mathrm{MW} / \mathrm{h})$

Ramp-down and ramp-up rate of the TES discharge (MW/h)

Area of photovoltaic mirror field $\left(\mathrm{m}^{2}\right)$

Start-up cost of the $i$ th thermal unit (\$)

Lower and upper bound of the BES state of charge

Temperature at period $t\left({ }^{\circ} \mathrm{C}\right)$

Minimum "on" time of the $i$ th thermal unit (h)

Minimum "off" time of the $i$ th thermal unit (h).

\section{Functions and Variables}

cost: $\quad$ Cost of total system $(\$)$

$\operatorname{cost}_{t}^{\mathrm{CSP}}$ : Cost of operating CSP units $(\$)$

$\operatorname{cost}_{t}^{\mathrm{WD}}$ : Cost of the operating wind power units $(\$)$

$\operatorname{cost}_{t}^{\mathrm{PV}}$ : Cost of the operating PV units (\$)

$\operatorname{cost}_{t}^{G}$ : Cost of the operating thermal units (\$)

$P_{t}^{\mathrm{CSP}}$ : $\quad$ Power output of the CSP unit at period $t$ (MW)

$P_{t}^{S P}: \quad$ Power output of the CSP unit from the SF at period $t$ (MW)

$P_{t}^{\mathrm{TP}}: \quad$ Power output of the CSP unit from the TES at period $t$ (MW)

$P_{t}^{\mathrm{WD}}: \quad$ Power output of the wind power unit at period $t$ (MW)

$P_{t}^{\mathrm{PV}}$ : $\quad$ Power output of the PV unit at period $t$ (MW)

$P_{t, i}^{G}: \quad$ Power output of the $i$ th thermal unit at period $t$ (MW)

$P_{t}^{\text {ch }}: \quad$ Power input of the BES unit at period $t(\mathrm{MW})$

$P_{t}^{\text {disch: }}$ Power output of the BES unit at period $t$ (MW)

$z_{t}^{\text {disch: }} \quad$ Binary variable representing commitment state of the BES discharge at period $t$

$q_{t}^{\text {SP }} \quad$ Thermal power from the SF utilized to produce electricity at period $t$ (MW)

$q_{t}^{\mathrm{TP}}: \quad$ Thermal power from the TES utilized to produce electricity at period $t$ (MW)

$q_{t}^{\mathrm{SF}}$ : Thermal power of TES utilized to produce electricity (MW)

$q_{t}^{\mathrm{SE}}: \quad$ Thermal power of the SF absorbs at period $t$ (MW)

$q_{t}^{\text {TES }}$ : Thermal energy stored in TES at the end of hour $t$ (MWh)

$\mathrm{SOC}_{t}$ : State of charge of the BES unit at period $t$

$U_{t}$ : Binary variable representing commitment state of thermal unit $i$ at period $t$

$z_{t}^{\text {ch }}$ Binary variable representing commitment state of the BES charge at period $t$.

\section{Data Availability}

The data used to support the findings of this study are included within the article.

\section{Conflicts of Interest}

The authors declare that there are no conflicts of interest regarding the publication of this paper.

\section{Acknowledgments}

This research was funded by the National Natural Science Foundation of China, Grant no. 51667013, and Science and Technology Projects of State Grid Corporation of China, Grant no. 5227221900V.

\section{References}

[1] S. R. Salkuti, "Day-ahead thermal and renewable power generation scheduling considering uncertainty," Renewable Energy, vol. 131, pp. 956-965, 2019.

[2] S. Zhao, Y. Fang, and Z. Wei, "Stochastic optimal dispatch of integrating concentrating solar power plants with wind farms," International Journal of Electrical Power \& Energy Systems, vol. 109, pp. 575-583, 2019.

[3] S. M. Hosseini, R. Carli, and M. Dotoli, "Robust optimal energy management of a residential microgrid under uncertainties on demand and renewable power generation," IEEE Transactions on Automation Science and Engineering, vol. 18, no. 2, pp. 618-637, 2021.

[4] M. A. Ortega-Vazquez and D. S. Kirschen, "Estimating the spinning reserve requirements in systems with significant wind power generation penetration," IEEE Transactions on Power Systems, vol. 24, no. 1, pp. 114-124, 2009.

[5] S. Eftekharnejad, V. Vittal, Heydt, B. Keel, and J. Loehr, "Impact of increased penetration of photovoltaic generation on power systems," IEEE Transactions on Power Systems, vol. 28, no. 2, pp. 893-901, 2013.

[6] M. S. Mahmoud, S. Azher Hussain, and M. A. Abido, "Modeling and control of microgrid: an overview," Journal of the Franklin Institute, vol. 351, no. 5, pp. 2822-2859, 2014.

[7] M. Mazidi, A. Zakariazadeh, S. Jadid, and P. Siano, "Integrated scheduling of renewable generation and demand response programs in a microgrid," Energy Conversion and Management, vol. 86, pp. 1118-1127, 2014.

[8] M. M. Esfahani, A. Hariri, and O. A. Mohammed, "A multiagent-based game-theoretic and optimization approach for market operation of multimicrogrid systems," IEEE Transactions on Industrial Informatics, vol. 15, no. 1, pp. 280-292, 2019.

[9] M. Sedighizadeh, M. Esmaili, A. Jamshidi, and M.-H. Ghaderi, "Stochastic multi-objective economic-environmental energy and reserve scheduling of microgrids considering battery energy storage system," International Journal of Electrical Power \& Energy Systems, vol. 106, pp. 1-16, 2019.

[10] R. Bahmani, H. Karimi, and S. Jadid, "Stochastic electricity market model in networked microgrids considering demand response programs and renewable energy sources," International Journal of Electrical Power \& Energy Systems, vol. 117, p. 105606, 2020.

[11] A. Ghanbari, H. Karimi, and S. Jadid, "Optimal planning and operation of multi-carrier networked microgrids considering multi-energy hubs in distribution networks," Energy, vol. 204, p. 117936, 2020.

[12] M. Sedighizadeh, S. M. M. Alavi, and A. Mohammadpour, "Stochastic optimal scheduling of microgrids considering demand response and commercial parking lot by 
AUGMECON method," Iranian Journal of Electrical and Electronic Engineering, vol. 16, pp. 393-411, 2020.

[13] H. A. Aalami, H. Pashaei-Didani, and S. Nojavan, "Deriving nonlinear models for incentive-based demand response programs," International Journal of Electrical Power \& Energy Systems, vol. 106, pp. 223-231, 2019.

[14] L. Ju, C. Qin, H. Wu, P. He, and Z. Tan, "Wind power accommodation stochastic optimization model with multi-type demand response," Power System Technology, 2015.

[15] Y. Song, Z. Tan, L. I. Huanhuan, and W. Liu, "An optimization model combining generation side and energy storage system with demand side to promote accommodation of wind power," Power System Technology, vol. 38, pp. 610-615, 2014.

[16] Y. Astriani, G. M. Shafiullah, and F. Shahnia, "Incentive determination of a demand response program for microgrids," Applied Energy, Article ID 116624, 2021.

[17] A. Ghasemi, S. S. Mortazavi, and E. Mashhour, "Hourly demand response and battery energy storage for imbalance reduction of smart distribution company embedded with electric vehicles and wind farms," Renewable Energy, vol. 85, pp. 124-136, 2016.

[18] H. Liu, J. Qi, J. Wang, P. Li, C. Li, and H. Wei, "EV dispatch control for supplementary frequency regulation considering the expectation of EV owners," IEEE Transactions on Smart Grid, vol. 9, no. 4, pp. 3763-3772, 2018.

[19] H. Liu, B. Wang, N. Wang et al., "Enabling strategies of electric vehicles for under frequency load shedding," Applied Energy, vol. 228, pp. 843-851, 2018.

[20] V. Lakshmanan, M. Marinelli, J. Hu, and H. W. Bindner, "Provision of secondary frequency control via demand response activation on thermostatically controlled loads: solutions and experiences from Denmark," Applied Energy, vol. 173, pp. 470-480, 2016.

[21] J. Wang, X. U. Jian, S. Liao, S. Liping, Y. Sun, and C. Wei, "Coordinated optimization of integrated electricity-gas energy system considering uncertainty of renewable energy output," Automation of Electric Power Systems, 2019.

[22] Y. Bao, J. Xu, W. Feng et al., "Provision of secondary frequency regulation by coordinated dispatch of industrial loads and thermal power plants," Applied Energy, vol. 241, pp. 302-312, 2019.

[23] S. Liao, J. Xu, Y. Sun, Y. Bao, and B. Tang, "Control of energyintensive load for power smoothing in wind power plants," IEEE Transactions on Power Systems, vol. 33, no. 6, pp. 6142-6154, 2018.

[24] M. Zhao, Z. Chen, and F. Blaabjerg, "Probabilistic capacity of a grid connected wind farm based on optimization method," Renewable Energy, vol. 31, no. 13, pp. 2171-2187, 2006.

[25] T. K. Shrestha and R. Karki, "Utilizing energy storage for operational adequacy of wind-integrated bulk power systems," Applied Sciences, vol. 10, no. 17, p. 5964, 2020.

[26] R. Hemmati, H. Saboori, and M. A. Jirdehi, "Stochastic planning and scheduling of energy storage systems for congestion management in electric power systems including renewable energy resources," Energy, vol. 133, pp. 380-387, 2017.

[27] M. Delfanti, D. Falabretti, and M. Merlo, "Energy storage for PV power plant dispatching," Renewable Energy, vol. 80, pp. 61-72, 2015.

[28] P. Denholm, Y.-H. Wan, M. Hummon, and M. Mehos, "The value of CSP with thermal energy storage in the western United States," Energy Procedia, vol. 49, pp. 1622-1631, 2014.

[29] I. Llorente García, J. L. Álvarez, and D. Blanco, "Performance model for parabolic trough solar thermal power plants with thermal storage: comparison to operating plant data," Solar Energy, vol. 85, no. 10, pp. 2443-2460, 2011.

[30] C. Hernández Moris, M. T. Cerda Guevara, A. Salmon, and A. Lorca, "Comparison between concentrated solar power and gas-based generation in terms of economic and flexibilityrelated aspects in Chile," Energies, vol. 14, no. 4, p. 1063, 2021.

[31] M. Dale, "A comparative analysis of energy costs of photovoltaic, solar thermal, and wind electricity generation technologies," Applied Sciences, vol. 3, no. 2, pp. 325-337, 2013.

[32] G. He, Q. Chen, C. Kang, and Q. Xia, "Optimal offering strategy for concentrating solar power plants in joint energy, reserve and regulation markets," IEEE Transactions on Sustainable Energy, vol. 7, no. 3, pp. 1245-1254, 2016.

[33] H. M. I. Pousinho, H. Silva, V. M. F. Mendes, M. CollaresPereira, and C. Pereira Cabrita, "Self-scheduling for energy and spinning reserve of wind/CSP plants by a MILP approach," Energy, vol. 78, pp. 524-534, 2014.

[34] Y. Cui, H. Zhang, W. Zhong, Y. Zhao, Z. Wang, and B. Xu, "Day-ahead scheduling considering participation of pricebased demand response and CSP plant in wind power accommodation," Power System Technology, vol. 44, 2020.

[35] M. Nasouri Gilvaei, M. Hosseini Imani, M. Jabbari Ghadi, L. Li, and A. Golrang, "Profit-based unit commitment for a GENCO equipped with compressed air energy storage and concentrating solar power units," Energies, vol. 14, no. 3, p. $576,2021$. 